\title{
Prolylcarboxypeptidase (PRCP) as a new target for obesity treatment
}

This article was published in the following Dove Press journal:

Diabetes, Metabolic Syndrome and Obesity:Targets and Therapy

15 April 2010

Number of times this article has been viewed

\author{
B Shariat-Madar' \\ D Kolte ${ }^{2}$ \\ A Verlangieri ${ }^{2}$ \\ Z Shariat-Madar ${ }^{2}$ \\ 'College of Literature, Science, and \\ the Arts, University of Michigan, \\ Ann Arbor MI, USA; ${ }^{2}$ School \\ of Pharmacy, Department \\ of Pharmacology, University \\ of Mississippi, University, \\ MS, USA
}

\begin{abstract}
Recently, we serendipitously discovered that mice with the deficiency of the enzyme prolylcarboxypeptidase (PRCP) have elevated $\alpha$-melanocyte-stimulating hormone $(\alpha-\mathrm{MSH})$ levels which lead to decreased food intake and weight loss. This suggests that PRCP is an endogenous inactivator of $\alpha-\mathrm{MSH}$ and an appetite stimulant. Since a modest weight loss can have the most profound influence on reducing cardiovascular risk factors, the inhibitors of PRCP would be emerging as a possible alternative for pharmacotherapy in high-risk patients with obesity and obesity-related disorders. The discovery of a new biological activity of PRCP in the PRCP-deficient mice and studies of $\alpha$-MSH function indicate the importance and complexity of the hypothalamic pro-opiomelanocortin (POMC) system in altering food intake. Identifying a role for PRCP in regulating $\alpha-\mathrm{MSH}$ in the brain may be a critical step in enhancing our understanding of how the brain controls food intake and body weight. In light of recent findings, the potential role of PRCP in regulating fuel homeostasis is critically evaluated. Further studies of the role of PRCP in obesity are much needed.
\end{abstract}

Keywords: prolylcarboxypeptidase, melanocyte-stimulating harmone, appetite, weight loss, cardiovascular risk, obesity

\section{Introduction}

The hypothalamus is often times a target for newer potential obesity treatments due to its crucial role in food intake and metabolism. It is also established that food intake modulation is confounded by numerous players within the hypothalamus, allowing for the research and development of a diverse array of obesity management drug leads that have completely different underlying mechanisms. The melanocortin system is established amongst these systems; however, the cannabinoid system, among others, also has an established role. Speculation of a connection between the cannabinoid system and melanocortin system regarding food intake has existed due to their presence in nearby regions of the hypothalamus. Moreover, suboptimal doses of SR 141716 (rimonabant) together with suboptimal doses of $\alpha$-melanocyte-stimulating hormone $(\alpha-\mathrm{MSH})$ are known to behave synergistically in order to reduce food intake. Attempts to develop a safe drug to treat obesity via blocking the $\mathrm{CB} 1$ receptor have proven to be elusive and controversial, as drugs such as rimonabant have had to struggle for approval due to numerous reported and suspected side effects, particularly depression. The role of the melanocortin system in food intake is well-established and prevention of the rapid inactivation of $\alpha$-MSH may prove to be a better alternative pathway for potential obesity treatments. Recent studies suggest that prolylcarboxypeptidase (PRCP) involved in regulating blood pressure and inflammation is an appetite stimulant
Correspondence: Zia Shariat-Madar University of Mississippi, 219 B

Faser Hall, University,

MS 38677-I848, USA

$\mathrm{Tel}+6629155150$

Fax +6629155148

Email madar@olemiss.edu 
and, by consequence, PRCP inhibitors may prove to be a viable lead to treat obesity.

There have been numerous excellent reviews on melanocortin receptors. ${ }^{1-6}$ However, this article only reports the most current information about how the two tectonic physiological processes, namely the proteolytic enzymes of renin-angiotensin system (RAS) and proopiomelanocortin (POMC)-derived neuropeptide regulatory processes in the central nervous system might be shifting toward each other. Recent findings suggest that PRCP (a RAS enzyme) regulates $\alpha$-MSH (a POMC-derived neuropeptide) levels, a theme addressed by the present review. While this article briefly introduces both PRCP- and $\alpha$-MSH-mediated processes, it also outlines how brain PRCP may play a key role in controlling food intake and weight gain.

\section{The current scope of prolylcarboxypeptidase}

The PRCP-catalyzed reaction was initially found to be part of the pathway for angiotensin II (Ang II) metabolism in renal tissues, where PRCP appeared to control the total amount of Ang II. Odya and others demonstrated that PRCP metabolizes
Ang II to angiotensin 1-7 (Ang 1-7) (Figure 1). ${ }^{7}$ The activation of Ang 1-7 receptor Mas (a G-protein-coupled protein) by Ang 1-7 results in the generation of nitric oxide (NO) and prostaglandins. ${ }^{8}$ Thus, Ang 1-7 counteracts Ang II function, providing evidence that PRCP regulates the negative effects of Ang II such as high blood pressure and heart failure. ${ }^{9}$ In addition, the activation of the Ang 1-7 receptor Mas may also lead to diminished cell proliferation through down-regulation of the phosphorylation and activation of Erk1 and Erk2 in the Erk1/Erk2 Map kinase signaling pathway. ${ }^{10,11}$ In theory, the PRCP inhibitors to target the production of pro-inflammatory prostaglandins and promote proliferation through the Ang 1-7 receptor Mas-dependent pathway represent a novel approach to suppress unwanted inflammation-causing prostaglandins.

Later, it was shown that PRCP is one of several enzymes that convert Ang II to a unique bioactive molecule. In vitro studies showed that angiotensin-converting enzyme 2 (ACE2) is an exopeptidase that converts Ang II to Ang 1-7 at a much faster rate than PRCP. ${ }^{12}$ These data suggest that Ang II is a poor substrate for PRCP. Clinical studies have provided reliable evidence that ACE2 is an essential regulator of angiotensin I (Ang I), Ang II, and angiotensin-induced cardiac

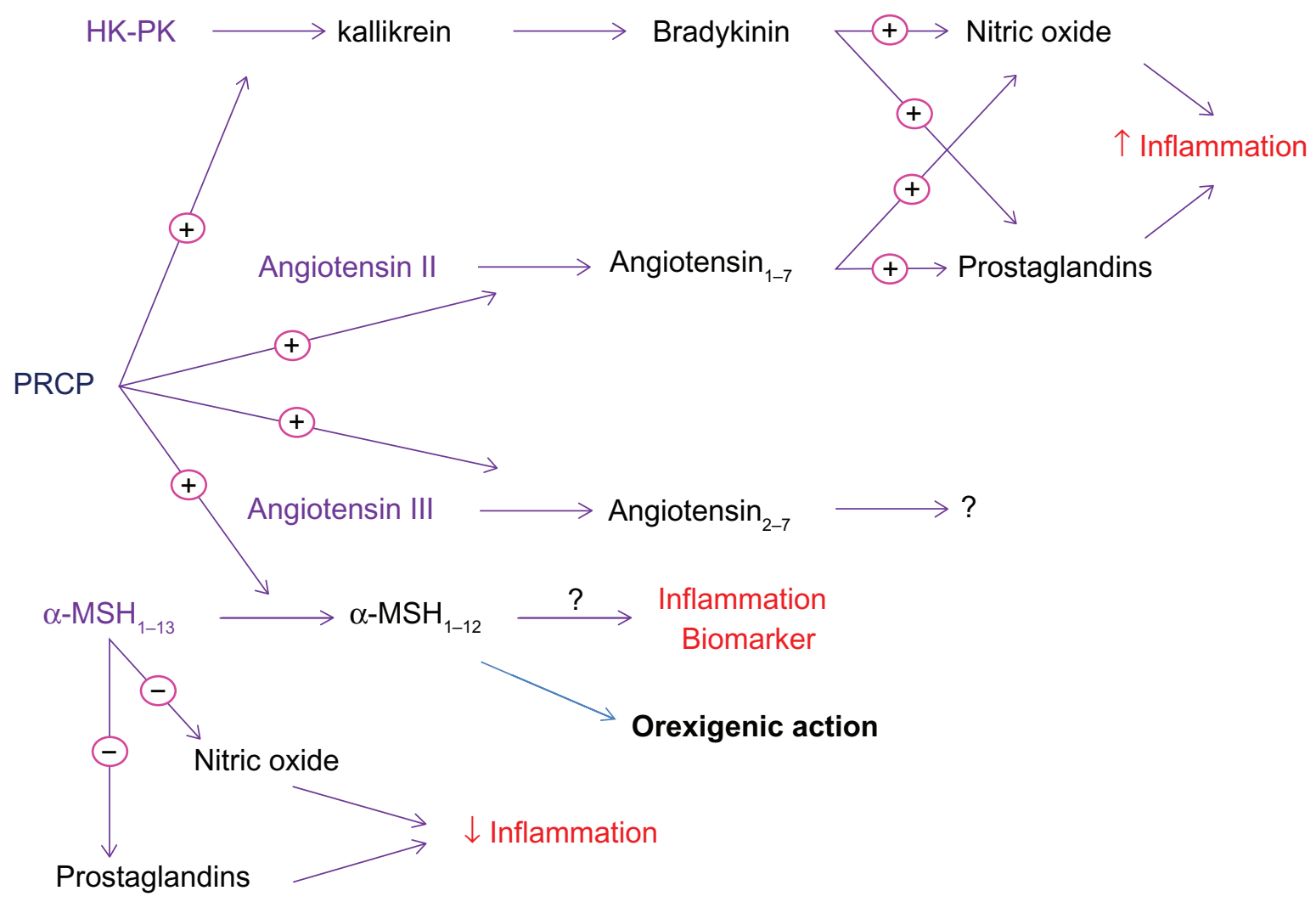

Figure I The physiological action of prolylcarboxypeptidase (PRCP).

Notes: PRCP elicits increased production of proinflammatory prostaglandins and vasodilatory nitric oxide and promotes orexigenic action through inactivation of $\alpha-\mathrm{MSH}$ Abbreviations: $\alpha-M S H, \alpha$-melanocyte-stimulating hormone; HK high molecular weight kininogen; PK, prekallikrein. 
hypertrophy. ${ }^{13}$ Recent studies clearly show increased myocardial levels of Ang II and a significant decrease in Ang 1-7 in ACE2-deficient hearts, suggesting that the role of PRCP in metabolizing Ang II may be insignificant. ${ }^{9}$ Taken together, these observations suggest that PRCP is a redundant catalyst contributing to alternate pathways for Ang II metabolism.

While the well-established cardiovascular and renal actions of Ang II are attributed to the angiotensin type 1 receptor (AT1R), much less is known about angiotensin III and its cardiovascular effects. For more than 30 years, it was known that PRCP metabolizes Ang III to Ang 2-7 (Figure 1). ${ }^{7}$ Soon after, studies demonstrated that Ang III is a pressor agent whose response, like that of Ang II, is mediated by AT1 receptors. ${ }^{14,15}$ Apparently, Ang III has multiple effects on renal function in the diseased kidney and can enhance renal disease through the overproduction of aldosterone, leading to arterial hypertension and/or atrial fibrillation. ${ }^{16}$ Aldosterone maintains blood volume, pressure, and electrolyte balance. Its production is known to be regulated by renin, an enzyme produced in the kidneys. Renin increases in response to low blood pressure, decreased blood flow to the kidneys, or sodium deficiency. The elevation of renin results in an increase in synthesis and secretion of aldosterone. Studies indicate that Ang III also activates the secretion of aldosterone.${ }^{15}$ Recently, we have demonstrated that recombinant PRCP (rPCRP) metabolizes Ang III to Ang 2-7, removing phenylalanine (Phe). ${ }^{8}$ It is tempting to speculate that PRCP might funnel the generation of angiotensin 3-4 (Ang 3-4) through Ang 2-7 (Figure 1). If the over-secretion of aldosterone by Ang III is viewed as a trigger of arterial hypertension, then inactivation of Ang III by PRCP might lead to a decrease in blood pressure. Further studies are required to determine whether PRCP is critically important for regulating Ang III-induced hypertension and preserving renal structure and function. This is an important area of research to pursue given the increasing prevalence of cardiovascular disease and stroke in the older population.

The possible actions of another substrate of PRCP, plasma prekallikrein (PK, Fletcher factor), have recently begun to receive much attention. When the complex of high molecular weight kininogen (HK) and PK binds to endothelial membrane, PK is rapidly converted to kallikrein by PRCP. ${ }^{17}$ The formed kallikrein then cleaves HK to liberate bradykinin (BK), which leads to NO and prostaglandin-I2 formation, as well as subsequent vasodilation, by activating constitutive bradykinin B2 and inducible bradykinin B1 receptors. ${ }^{18,19}$ The PRCP-dependent PK activation pathway might be considered an additional mechanism to preserve the availability of $\mathrm{NO}$ and prostacyclin as vasodilatory agents in vascular smooth muscle. We proposed that chronic PRCP inhibition might elevate blood pressure. In accordance, we have found that $\mathrm{PRCP}^{\mathrm{g} t \mathrm{gt}}$ mice have mild hypertension, suggesting a causative relationship between PRCP levels and signs of hypertension. ${ }^{20}$

Local skeletal muscle ischemia and acidosis are shown to increase the generation of $\mathrm{BK}$ and prostaglandins, the two circulating products of the PRCP-induced cell activation (Figure 1). ${ }^{21}$ The increased acidotic response during exercise and inflammatory mediators such as BK and prostacyclin have been shown to cause abnormal exercise-related symptoms and autonomic responses in congestive heart failure syndrome. ${ }^{22}$ Nonetheless, the long-term elevated concentrations of $\mathrm{NO}$ and prostacyclin through PRCP-dependent pathways may be detrimental and eventually responsible for cardiovascular diseases such as congestive heart disease. Since BK and Prostaglandins exacerbate the genesis of the symptoms of exercise intolerance in heart failure, ${ }^{23}$ the inhibitors of PRCP might be effective in ameliorating the exercise-limiting symptoms.

Clinical studies demonstrate that PRCP is involved in the pathogenesis of inflammatory conditions such as rheumatoid arthritis and infection. ${ }^{24}$ Melanocortin peptides have numerous effects on the host such as the modulation of fever, inflammation and appetite. ${ }^{25}$ Recently, we showed that PRCP metabolizes alpha-melanocyte-stimulating hormone 1-13 $\left(\alpha-\mathrm{MSH}_{1-13}\right)$ to alpha-melanocyte-stimulating hormone $1-12\left(\alpha-\mathrm{MSH}_{1-12}\right),{ }^{26}$ (Figure 1). $\alpha-\mathrm{MSH}_{1-13}$ is a potent anti-inflammatory agent. ${ }^{27}$ In addition to the specificity of cleavage, the cellular release of pro-inflammatory mediators seemed to be critical to PRCP actions. In theory, agents that increase production and effects of $\alpha-\mathrm{MSH}_{1-13}$ could be used to counteract the effects of pro-inflammatory mediators such as bradykinin and cytokines (Figure 1).

Obesity is known to cause inflammation and insulin resistance in the vasculature and non-vascular tissues involved in glucose metabolism. ${ }^{28}$ Evidence suggests that hyperglycemia may contribute to defective NO-dependent vasodilation in diabetes..$^{29}$ The inducible NO synthase (iNOS) expression is elevated in adipose tissue of obese people compared to those of lean people ${ }^{30}$ and is a mediator of inflammation and a key enzyme in insulin resistance. ${ }^{31}$ The colocalization of $\alpha-\mathrm{MSH}_{1-13}$ receptors (MC4R) with iNOS has been reported, suggesting a role for $\alpha-\mathrm{MSH}_{1-13}$ in obese people. ${ }^{32}$ The inactivation of $\alpha-\mathrm{MSH}_{1-13}$ by PRCP provides a positive feedback loop for postprandial enhancement of food intake and inflammation by inhibiting $\alpha-\mathrm{MSH}_{1-13}$ function, as shown in Figure $2 .{ }^{26}$ Since PRCP regulates the anorectic action of $\alpha-\mathrm{MSH}_{1-13}$, this study highlights 


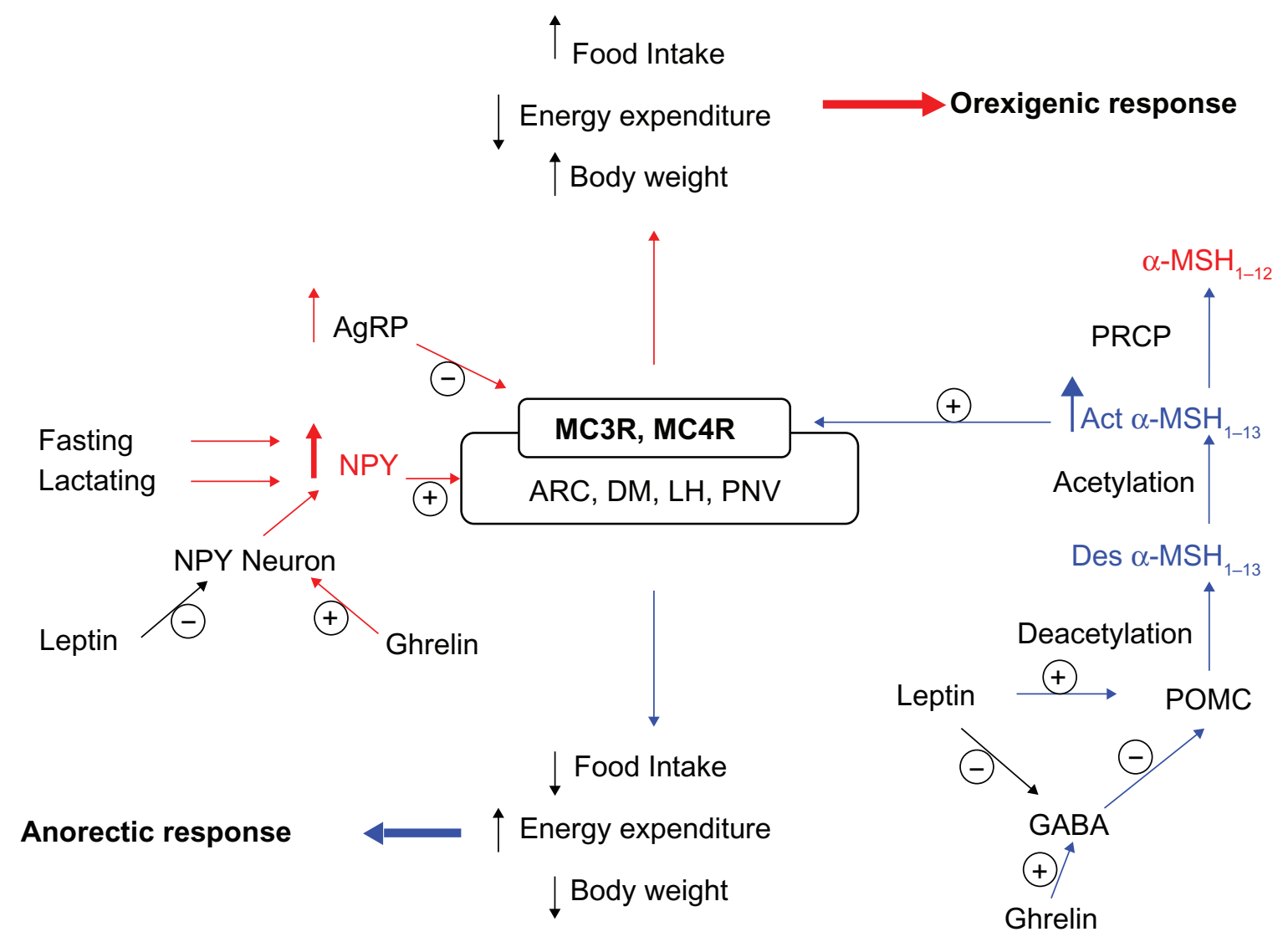

Figure 2 The role of the hypothalamus in food intake and metabolism.

Notes: The catalysis of $\alpha-\mathrm{MSH}_{1-13}$ to $\alpha-\mathrm{MSH}_{1-12}$ by PRCP leads to increased food intake and body weight gain in humans. Blue arrows indicate anorectic response and red arrows indicate orexigenic response.

Abbreviations: Act- $\alpha-M S H$, acetylated $\alpha-M S H ;$ AgRP, Agouti-related protein; ARC, arcuate nucleus of the hypothalamus; Des- $\alpha-M S H$, desacetyl $\alpha-M S H ;$; M, dorsomedial hypothalamus; GABA, gamma-aminobutryric acid; LH, lateral hypothalamus; MC3R, melanocortin-3 receptor; MC4R, melanocortin-4 receptor; NPY, neuropetide y; POMC, pro-opiomelanocortin; PVN, paraventricular nucleus.

the presence of a newly recognized interaction between inflammation, obesity, and the expression and activity of PRCP (Figure 2). ${ }^{26}$ In view of the above studies, we consider that PRCP may be a key player in the obesity-associated metabolic complications, inflammatory response, and the host defense mechanism.

\section{Prolylcarboxypeptidase's physiological function and relationship with hypothalamic appetite-regulating pathways}

The following sections emphasize pertinent findings, which best describe the theoretical perspective on the components of the central melanocortin system and stress the importance of PRCP influence in the melanogenic signaling pathway.

Synthesis of $\alpha$-melanocyte - stimulating hormone Pro-opiomelanocortin (POMC), a prohormone with molecular weight of $31 \mathrm{kDa}$, is ubiquitously expressed in various tissues of mammals. ${ }^{33,34}$ POMC expression in the central nervous system, however, is limited to the arcuate nucleus of the hypothalamus (ARC), nucleus tractus solitarius of the caudal medulla (NTS), and corticotrophs and melanotrophs of the anterior pituitary (Figure 2). ${ }^{35}$ The 1200 base pair POMC transcript encodes for the 267 amino acid prohormone with an N-terminal signal peptide of 26 residues. ${ }^{36}$ As this precursor peptide passes through the Golgi stacks, it is targeted, via a specific signal peptide, into regulated secretory granules. ${ }^{37}$ POMC undergoes extensive posttranslational modification within these secretory granules mediated by a family of serine proteases, the prohormone convertases (PCs), as illustrated in Figure 3.

POMC is cleaved by prohormone convertase 1 (PC1) to produce $22 \mathrm{kDa}$ pro-ACTH and $\beta$-lipoprotein hormone $(\beta$-LPH) (Figure 3). ${ }^{38}$ Pro-ACTH is further cleaved by $\mathrm{PC} 1$ to produce the N-terminus of POMC-joining peptide and $4.5 \mathrm{kDa}$ ACTH. Prohormone convertase 2 (PC2) cleaves ACTH to ACTH 1-17 and corticotropin-like intermediate lobe peptide (CLIP) and $\beta$-LPH to $\gamma$-lipoprotein hormone $(\gamma$-LPH) and $\beta$-endorphin 


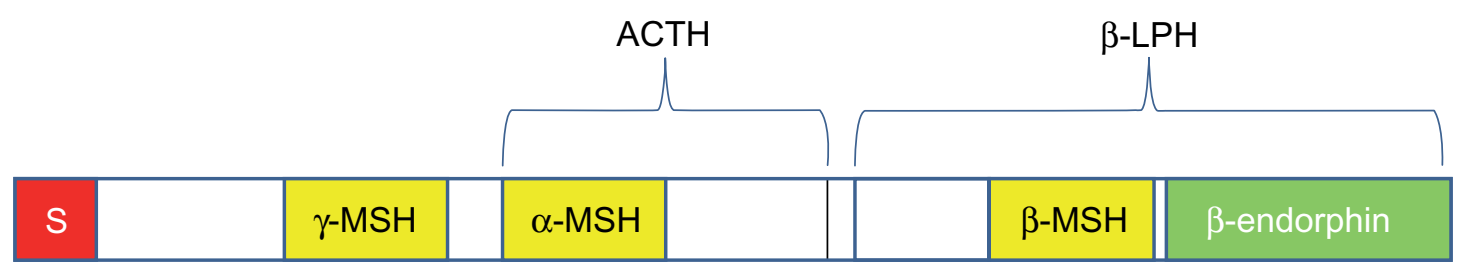

Figure 3 Schematic structure of pro-opiomelanocortin (POMC) and location of melanocyte-stimulating hormones (MSH).

Abbreviations: ACTH, adrenocorticotropic hormone; $\beta$-LPH, beta-lipotropic hormone; $\mathrm{S}$, signal sequence; $\gamma-\mathrm{MSH}$, gamma-MSH; $\alpha-\mathrm{MSH}$, alpha-MSH; $\beta$-MSH, beta-MSH; $\beta$-endorphin, beta-endorphin.

(Figure 3). $\gamma$-LPH and the N-terminus of POMC are further modified to produce $\beta$-MSH and $\gamma$-MSH, respectively.

$\alpha-\mathrm{MSH}$ is a tridecapeptide derived from POMC. The synthesis of $\alpha$-MSH from POMC involves several specific enzymes in addition to PC1 and PC2. First, carboxypeptidase $\mathrm{E}$ cleaves the $\mathrm{C}$-terminal basic amino acid residues of ACTH 1-17. The peptide is then amidated by peptidyl $\alpha$-amidating monooxygenase (PAM) to produce desacetyl $\alpha$-MSH (Des- $\alpha-\mathrm{MSH})$. Finally, Des- $\alpha-\mathrm{MSH}$ is acetylated by $\mathrm{N}$-acetyltransferase (NAT) to produce acetylated $\alpha$-MSH (Act- $\alpha-\mathrm{MSH}$ ), as illustrated in Figure 2. Act- $\alpha-\mathrm{MSH}$ is more potent than Des- $\alpha-\mathrm{MSH}$ in activating melanocortin receptor signaling and in reducing food intake, effects that are likely due to rapid degradation of Des- $\alpha-\mathrm{MSH}$. Guo et al have shown that total hypothalamic $\alpha$-MSH levels are decreased in leptin-deficient $o b / o b$ mice and increased in leptin-treated $o b / o b$ and C57BL/6J mice. Leptin specifically enhances hypothalamic levels of Act- $\alpha-\mathrm{MSH}$ without significantly affecting the amounts of Des- $\alpha-\mathrm{MSH}$, possibly by activating NAT in the POMC neurons. ${ }^{39}$

\section{Five distinct central melanocortin receptors with different physiological functions}

The melanocortin receptors are G-protein-coupled receptors with characteristic seven transmembrane domains. So far, five melanocortin receptors have been identified in humans - MC1R-MC5R. ${ }^{40-43}$ The melanocortin receptors are $\mathrm{G}_{\mathrm{s}}$-coupled and signal via the adenylate cyclase-cAMP-protein kinase A second messenger pathway. However, depending on the cell type and the melanocortin receptor expression, signal transduction pathways other than cAMP may be activated which include inositol triphosphate-diacyl glycerol-protein kinase C (IP3-DAG-PKC) pathway, extracellular $\mathrm{Ca}^{2+}$ influx, MAP kinase pathway, and the JAK/STAT pathway. ${ }^{44-48}$ MC1R, MC3R, MC4R and MC5R show 40\%-60\% amino acid homology. The natural MSH peptides have a conserved sequence, His-Phe-Arg-Trp, which plays an important role in the binding of these peptides to specific melanocortin receptors. ${ }^{49}$
$\mathrm{MC1R}$ was the first melanocortin receptor to be cloned and was isolated from human melanoma cell line..$^{40} \alpha$-, $\beta$ - and $\gamma$-MSH and ACTH are the known agonists whereas agouti is the known antagonist of the MC1R. MC1R is expressed in human and mouse melanoma cells, human melanocytes, skin glands, and hair follicles. ${ }^{40,50-53} \alpha$-MSH, agouti, and MC1R, therefore, play an important role in regulating skin pigmentation and hair color. The presence of MC1R in the testes and the pituitary has been demonstrated by Chhajlani et al. ${ }^{54} \mathrm{MC} 1 \mathrm{R}$ expression in the central nervous system is limited to neurons of the periaqueductal grey in both rat and human brain. ${ }^{55}$ However, MC1R is widely expressed in cells involved in inflammation such as endothelial cells, neutrophils, monocytes, macrophages, fibroblasts and astrocytes. ${ }^{25,56-59}$ $\alpha$-MSH has been shown to inhibit inflammation via MC1R-mediated decrease in the production of inflammatory cytokines such as IL-1, IL-6, and tumor necrosis factor-alpha $(\mathrm{TNF} \alpha)$, as well as suppression of NF- $\kappa \mathrm{B} \cdot{ }^{60-62}$

$\mathrm{MC} 2 \mathrm{R}$ is encoded by a single gene localized to chromosome 18p11.2. ${ }^{53} \mathrm{ACTH}$ is the only known agonist of the MC2R. ${ }^{63}$ Using in situ hybridization, Xia et al showed that MC2R is highly expressed in the adrenal cortex with the highest expression in the zona fasciculata and zona glomerulosa and relatively low expression in the zona reticularis. ${ }^{64}$ These findings are consistent with the role of $\mathrm{MC} 2 \mathrm{R}$ in mediating the effect of $\mathrm{ACTH}$ on the synthesis and release of corticosteroids. Besides the adrenal cortex, $\mathrm{MC} 2 \mathrm{R}$ is expressed in murine adipocytes, which explains the lipolytic effect of ACTH. ${ }^{59}$ However, human adipocytes do not express MC2R and there is no evidence to suggest that human adipose tissue is responsive to the lipolytic effect of ACTH. ${ }^{54}$ These species differences in the expression of MC2R may be important when studying the role of melanocortins in obesity. MC2R expression has also been demonstrated in the skin along with three cytochrome enzymes involved in steroid hormone synthesis. ${ }^{65}$ Kapas et al have shown that ACTH produced in the skin by keratinocytes stimulates DNA synthesis and induces cell proliferation via $\mathrm{MC} 2 \mathrm{R} .{ }^{66} \mathrm{MC} 2 \mathrm{R}$, therefore, appears to play an important role in cutaneous pathophysiology. 
MC3R is encoded by a single gene localized to the q13.2-q13.3 region of chromosome $20 .{ }^{67}$ Since this locus is associated with type 2 noninsulin-dependent diabetes mellitus (NIDDM), Mc $3 r$ could represent a candidate gene for NIDDM. ${ }^{68} \mathrm{MC} 3 \mathrm{R}$ is unique in that it binds to $\alpha-, \beta$ - and $\gamma-\mathrm{MSH}$ with similar affinities. Using Northern blot hybridization and polymerase chain reaction, Gantz et al first showed that MC3R is expressed in brain, placental, and gut tissues but not in melanoma cells or in adrenal glands. ${ }^{69}$ MC3R expression in the brain is highest in the hypothalamus especially in the arcuate nucleus, ventromedial nucleus, preoptic nucleus, lateral hypothalamic area, and posterior hypothalamic area. ${ }^{43}$ Agouti-related protein (AgRP), which is normally expressed in the hypothalamus, is a potent antagonist of both MC3R and MC4R. ${ }^{70}$ However, POMC and AgRP neurons in the arcuate nucleus of hypothalamus selectively express MC3R, and not MC4R, suggesting that MC3R might function as a presynaptic autoreceptor regulating the release of melanocortins. ${ }^{71,72}$ Physiological support for this hypothesis was provided by Cowley et al, ${ }^{73}$ who demonstrated that the selective MC3R agonist, D-Trp- $\gamma$-MSH inhibited firing of GFP-labeled POMC neurons in the PVN. Also, Marks et al showed that peripheral administration of the MC3R agonist stimulates feeding via MC3R-mediated inhibition of the ARC POMC neurons. ${ }^{74}$

An association between MC3R and human obesity has been identified by linkage studies. Several sequence variants have been found in the $M c 3 r$ coding region and in 5' flanking sequences. ${ }^{75} \mathrm{Mc} 3 r$ variants are associated with subtle changes in weight, leptin levels, and insulin-glucose ratios, but none of these explain human morbid obesity. ${ }^{76}$ A novel heterozygous mutation I183N in $M c 3 r$ was identified in two obese patients of the same family. ${ }^{77}$ Functional characterization of I183N showed that this mutation completely abolished the activity of the mutated receptor to stimulate intracellular cAMP production, suggesting that $1183 \mathrm{~N}$ might play an important role in obesity.$^{78}$ Similarly, Tao et al showed that a novel mutation I335S in $M c 3 r$ results in complete loss of ligand binding and signaling suggesting that this mutation might contribute to obesity. ${ }^{79}$ However, a recent study evaluating the functional consequences of all mutations found in $M c 3 r$ and $M c 4 r$ in severely obese North American adults concluded that $M c 4 r$, but not $M c 3 r$ mutations are associated with severe obesity in this population. ${ }^{80}$ Thus, the significance of $M c 3 r$ mutations in human obesity is still not conclusively established to date.

MC4R was first cloned by Gantz et al in $1993 .{ }^{42} \mathrm{MC} 4 \mathrm{R}$ is a 332 amino acid protein encoded by a single gene, localized to chromosome 18q21.3. Using Northern blot analysis and in situ hybridization, MC4R was originally found to be expressed primarily in the brain. MC4R expression was notably absent in the adrenal cortex, melanocytes, and placenta. ${ }^{42} \mathrm{MC} 4 \mathrm{R}$ is widely distributed in the central nervous system, especially in the cortex, hippocampus, amygdala, septum, corpus striatum, nucleus accumbens, hypothalamus, nucleus tractus solitarius, visual and motor nuclei of the brainstem, and the dorsal horn of the spinal cord. ${ }^{81} \alpha-\mathrm{MSH}$, $\beta-\mathrm{MSH}$, and $\mathrm{ACTH}$ are the known agonists and $\mathrm{AgRP}$ is the known antagonist of the MC4R (Figure 2). ${ }^{70}$

Since MC4R is highly expressed in the hypothalamus and has a strong affinity for $\alpha-\mathrm{MSH}$ it is believed to be a strong candidate for energy balance, appetite control, and body weight regulation. $M c 4 r$ knockout mice have been shown to develop a maturity onset obesity syndrome characterized by hyperphagia, hyperglycemia and hyperinsulinemia. ${ }^{82}$ Since this syndrome is similar to the agouti obesity syndrome seen in $A v y /$ - mice and AgRP-transgenic mice that overexpress agouti and AgRP respectively, it is speculated that the primary mechanism by which agouti and AgRP produce obesity is chronic antagonism of MC4R. ${ }^{83}$ Cachexia, a chronic wasting syndrome characterized by loss of body weight and muscle mass, is commonly associated with diseases such as cancer and AIDS. $M C 4 R^{--}$mice and mice treated with AgRP are resistant to lipopolysaccharide- or tumor-induced cachexia, further supporting the role of MC4R in energy balance and body weight regulation. ${ }^{84}$

MC5R is a 325 amino acid protein encoded by a single gene located on chromosome 18p11.2. ${ }^{85}$ MC5R has been shown to bind to all melanocortins except $\gamma-\mathrm{MSH} .{ }^{86} \mathrm{MC} 5 \mathrm{R}$ is the most widely expressed melanocortin receptor. MC5R mRNA is expressed in the adrenal gland, adipose tissue, kidney, leukocytes, lung, lymph node, mammary gland, ovary, pituitary, testis, and uterus. ${ }^{54} \mathrm{Mc} 5 r$ is highly expressed in exocrine glands such as lacrimal, preputial, Harderian and sebaceous glands. ${ }^{87} M c 5 r$-deficient mice have a severe defect in water repulsion and thermoregulation due to decreased production of sebaceous lipids. MC5R may therefore play an important role in peripheral thermoregulation. Studies in humans have shown that MC5R immunoreactivity is detectable in the epithelium and appendages, including the sebaceous, eccrine, and apocrine glands. However, analysis of $M c 5 r$ variations in patients with acne, hidradenitis suppurativa, and sebaceous gland dysfunction have failed to suggest a causative role of MC5R in these conditions. ${ }^{88}$ Low levels of MC5R mRNA have also been reported in the central nervous system, ${ }^{89}$ however, the physiological function of MC5R in the brain remains unclear. Linkage analysis in 
the Quebec Family Study ${ }^{90}$ revealed a significant association of $M c 5 r$ polymorphisms with body mass index, fat mass, and resting metabolic rate, thus providing some evidence for the possible role of MC5R in energy balance and body weight regulation.

\section{Appetite is tightly controlled by the relative hypothalamic levels of $\alpha-\mathrm{MSH}$}

$\mathrm{ARC}$ is the major site of POMC expression in the central nervous system. The POMC neurons, which produce $\alpha-\mathrm{MSH}$, also express another anorectic peptide cocaineamphetamine-related transcript (CART). Cell bodies of the POMC/CART neurons are found throughout the rostrocaudal extent of the arcuate nucleus, as well as the periarcuate area of the hypothalamus. Within the hypothalamus, these neurons project to the periventricular nucleus, paraventricular nucleus (PVH), and the perifornical region. ${ }^{91,92}$ The POMC/CART neurons also project to the brainstem to innervate the rostral NTS, lateral reticular nucleus, ventrolateral medulla, nucleus ambiguous, and the spinal cord, as reviewed elsewhere. ${ }^{93}$ Another critical component of the central melanocortin system within the ARC is the neurons expressing neuropeptide $\mathrm{Y}$ (NPY) and the potent MC3R/MC4R antagonist AgRP (Figure 2). The NPY/AgRP neurons have the same distribution as the POMC/CART neurons within the hypothalamus, with the densest fibers innervating the $\mathrm{PVH}$, dorsomedial hypothalamus (DMH), posterior hypothalamus, and septal regions around the anterior commissure. ${ }^{94}$

The NPY/AgRP neurons form synapses with the POMC/ CART neurons within the ARC, thus producing a neuronal network that is responsive to the modulatory effects of several appetite and body weight regulating hormones such as leptin, ghrelin, insulin, and peptide YY (PYY). ${ }^{73,95-98}$ Leptin acts via hypothalamic receptors $(\mathrm{Ob}-\mathrm{R})$ to decrease feeding and increase thermogenesis, resulting in a decrease in body weight. POMC/CART and NPY/AgRP neurons in the ARC are the principal sites of leptin receptor expression and the source of potent neuropeptide hormones, $\alpha$-MSH and NPY, which exert opposing effects on feeding and metabolism as shown in Figure 2. Subpopulations of NPY/AgRP neurons that also express gamma-aminobutyric acid (GABA) send inhibitory collaterals to the POMC/CART neurons. GABA inhibits the POMC/CART neurons and blocks the anorexic effect of $\alpha$-MSH (Figure 2). ${ }^{99}$ Using electrophysiological techniques, Cowley et al showed that leptin stimulates the POMC/CART neurons via two mechanisms: 1) depolarization through a nonspecific cation channel and 2) hyperpolarization of
NPY/AgRP neurons, leading to a reduction in the release of GABA that, in turn, causes disinhibition of the POMC/CART neurons (Figure 2). ${ }^{73}$

Ghrelin, the endogenous ligand for growth hormone secretagogue receptor (GHS-R), is a potent stimulant of growth hormone release and plays an important role in appetite control and body weight regulation. Circulating ghrelin levels are markedly increased with fasting and before meals and decrease following meals. ${ }^{100,101}$ Plasma ghrelin levels are also influenced by long-term energy balance and are increased in anorexia and decreased in obesity. ${ }^{102,103}$ Within the ARC, GSH-R is expressed on the NPY/AgRP neurons which are thought to mediate the orexigenic effects of ghrelin. Central and peripheral administration of ghrelin induces c-Fos in these neurons and increases hypothalamic NPY and AgRP mRNA expression, thus antagonizing the anorexic effects of leptin. ${ }^{95,98,104}$ Also, electrophysiological studies have shown that ghrelin directly activates the orexigenic NPY/AgRP neurons while coordinately inhibiting the anorexogenic POMC/CART neurons via increased GABA release on them (Figure 2). ${ }^{105}$ Stimulation of food intake by ghrelin is blocked by administration of NPY antagonist and is reduced in $N P Y^{-/-}$mice. ${ }^{95}$ Lastly, MC3R and MC4R knockout mice show reduced sensitivity to ghrelin as evidenced by decreased ghrelin-induced food intake and growth hormone secretion, thus suggesting an important role of MC3R and MC4R in mediating the orexigenic effects of ghrelin. ${ }^{106}$

NPY is a potent hypothalamic orexigenic peptide, probably the most powerful stimulant of appetite known. NYP mRNA expression in the hypothalamus is significantly increased during lactation and fasting. ${ }^{107}$ Central administration of NPY causes robust increase in food intake and body weight in rats. ${ }^{108,109}$ Chronic intracerebroventricular administration of NPY to normal rats produces hyperphagia, hyperinsulinemia, and liver and adipose tissue lipogenesis, thus mimicking the hormonal and metabolic changes of obesity. ${ }^{110}$ Recent evidence suggests that ectopic overexpression of NPY in other areas of the hypothalamus such as PVH, lateral hypothalamus, and DMH also increases food intake and body weight and that NPY knockdown in the DMH ameliorates the hyperphagia, obesity, and diabetes of Otsuka Long-Evans Tokushima Fatty (OLETF) rats. ${ }^{11,112}$ Thus, NPY in the hypothalamus plays an important role in modulating food intake and body weight (Figure 2).

NPY exerts its orexigenic effects probably by inhibiting the ARC POMC/CART neurons via its Y2 receptor. ${ }^{113}$ NPY is metabolized by several peptidases in the plasma. Recent 
evidence suggests that NPY $(1-36)$ is metabolized into three major fragments: NPY(3-36), NPY(3-35), and NPY(2-35), upon incubation with human serum. ${ }^{114}$ Specific inhibitors of dipeptidyl peptidase 4, plasma kallikrein, and aminopeptidase P prevent the production of NPY(3-36), NPY(3-35), and NPY(2-36), respectively. Plasma kallikrein metabolizes NPY(3-36) to NPY(3-35). Since NPY(3-35) is unable to bind to NPY Y1, Y2, and Y5 receptors, NPY(3-35) may represent the major metabolic end product of the Y2/Y5 agonist, NPY(3-36).

\section{Insight into the physiological functions of PRCP through genetic studies in mice}

A recent study identified two splice variants of PRCP; the second isoform was named Prcp2 (NCBI: NM_199418). Unlike Prcp, Prcp 2 has a longer transcript and a unique amino-terminal region. Although its full-length sequence is known, there is no evidence suggesting whether PRCP2 mRNA encodes a functional protein. ${ }^{24}$

The Prcp gene is speculated to be a candidate gene for essential hypertension. ${ }^{115}$ Mutational analysis of the human PRCP has led to a better understanding of PRCP-catalyzed reactions. Certain putative mutant forms of human PRCP apparently predispose the polymorphic carriers to cardiovascular diseases including hypertension and the risk of preeclampsia. ${ }^{116}$ The E112D polymorphism in the Prcp gene leads to increased antihypertensive effect of benazepril treatment in hypertensive patients. ${ }^{117}$ We have also demonstrated that PRCP ${ }^{\mathrm{gt} / \mathrm{gt}}$ mice have mild hypertension. ${ }^{20}$ Our recent studies demonstrated that the Prcp-null ( $\mathrm{PRCP}^{-/-}$) mice ate less and had even less fat than the mice with partial loss of the enzyme. ${ }^{26}$ These observations suggest that PRCP is a genetic marker for weight regulation and putative PRCP single nucleotide polymorphism (SNP) variants are associated with mild hypertension. Continued identification of $P R C P$ mutations, full-characterization of $P R C P$ knockout mice, and studies with knock-in mice with $P R C P / P R C P$ mutations will provide evidence that PRCP is a disease-causing gene for both obesity and hypertension. Meanwhile, we propose that the use of PRCP inhibitors should be strongly indicated by a diagnosis of obesity in patients with no systolic or diastolic deterioration.

\section{Future perspectives}

Obesity is an emerging worldwide public health hazard and is associated with significant morbidity and mortality. Although the physiological determinants of normal/abnormal eating behavior have been investigated, the underlying causes and mechanisms of dysregulation of food intake in obesity, type 2 diabetes, and metabolic syndrome are not well understood. The long-lasting challenge for clinicians and scientists in basic research to unfold the major cause of the dysregulation of the food intake is becoming close to the last battle. Clinical studies indicate that the molecular and cellular mechanisms by which leptin and alpha-melanocyte stimulation hormone $(\alpha-\mathrm{MSH})$ modulate each other's activity result in the regulation of food intake and energy expenditure. ${ }^{118}$ These studies suggest that $\alpha-\mathrm{MSH}$ is intimately involved in the regulatory mechanism of obesity, energy expenditure, and body weight.

Recently, prolylcarboxypeptidase (PRCP) was found to be responsible for the control of food intake and energy expenditure at a central level. The molecular mechanisms underlying the suppression of food intake in PRCP-deficient mice or by the inhibitor of PRCP clearly provide physiological evidence that PRCP is an inactivator of $\alpha-\mathrm{MSH} .{ }^{26}$ Thus, PRCP is emerging as a new identity involved in the control of food intake and energy metabolism.

Since $\alpha$-MSH can activate both melanocortin 4 receptors (MC4R) and melanocortin 1 receptors (MC1R) in a decreasing order, the catalysis of $\alpha-\mathrm{MSH}_{1-13}$ to $\alpha-\mathrm{MSH}_{1-12}$ by PRCP would lead to the suppression of both MC4R and MC1R activation as shown in Figure 4. Although there are various contributing factors for obesity, the recent research findings indicate that PRCP is involved in the development of weight gain and obesity. PRCP controls the balance between energy intake and energy expenditure via an $\alpha-\mathrm{MSH}_{1-13}$-mediated mechanism. An increase in PRCP expression or activity may result in obesity due to an imbalance between energy intake and energy expenditure. Although regulation of $\alpha-\mathrm{MSH}_{1-13}$-mediated MC4R activation described above is demonstrably important, the importance of the role of PRCP on the signaling mechanisms of MC1R in anti-inflammatory response remains an enigma (Figure 4). ${ }^{119}$ Additional studies are needed to determine whether or not PRCP regulates $\alpha-\mathrm{MSH}_{1-13}$-mediated MC1R activation.

The cellular role of PRCP is beginning to be unraveled both at the molecular and physiological levels. The human PRCP mutation studies exhibit associations with diseases such as hypertension and preeclampsia. The upregulation of human PRCP expression during inflammation has been described. ${ }^{24}$ On other hand, the PRCP knockout mice study demonstrates that PRCP is an appetite stimulant. Therefore, the pleiotropic effects of PRCP include increased NO and prostaglandin bioavailability, decreased vasoconstriction, and increased appetite. 


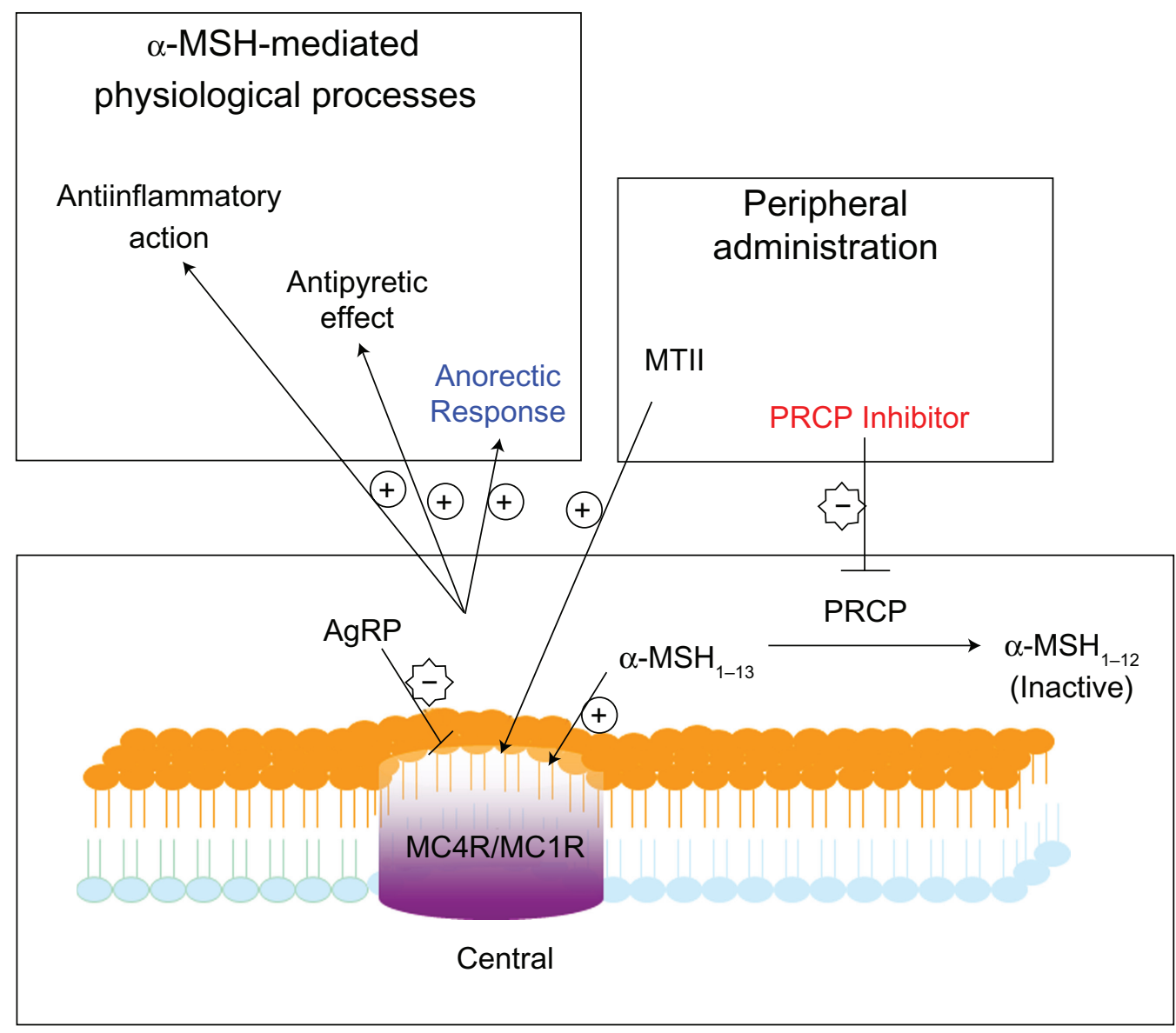

Figure 4 PRCP inhibitors provoke accumulation of $\alpha-\mathrm{MSH}_{1-13}$ peptide leading to reduced body weight, inflammation, and pain.

Abbreviations: $\alpha-\mathrm{MSH}_{1-13}$, a proopiomelanocortin (POMC) cleavage product; MC4R, melanocortin-4 receptor; MCIR, melanocortin-I receptor; predominant receptors of $\alpha-\mathrm{MSH}_{1-13} ; \mathrm{AgRP}$, agouti-related protein; endogenous MC4R antagonist; MTII, MC4R agonist; and prolylcarboxypeptidase (PRCP), endogenous inactivator of $\alpha-M S H_{1-13}$.

In summary, knowledge of the role of PRCP in mouse appetite regulation has provided a new view of the ability of PRCP to influence obesity. Thus, research on PRCP- $\alpha$ MSH interactions may be important to the further understanding of human obesity. In addition, the identification of PRCP as an inactivator of $\alpha$-MSH should provide an attractive therapeutic target in the fight against obesity. However, due to its pleiotropic effects, the PRCP inhibitors must be scrutinized carefully to optimize their use in the treatment and prevention of obesity and obesity-related diseases.

\section{Acknowledgment}

This study was supported by NCRR/NIH P20RR021929 to $\mathrm{SZ}$.

\section{Disclosures}

The authors declare that they have no competing interests, financial or otherwise with this work.

\section{References}

1. Eves PC, MacNeil S, Haycock JW. Alpha-Melanocyte stimulating hormone, inflammation and human melanoma. Peptides. 2006;27:444-452.

2. Lasaga M, Debeljuk L, Durand D, et al. Role of alpha-melanocyte stimulating hormone and melanocortin 4 receptor in brain inflammation. Peptides. 2008;29:1825-1835.

3. Oktar BK, Alican I. Modulation of the peripheral and central inflammatory responses by alpha-melanocyte stimulating hormone. Curr Protein Pept Sci. 2002;3:623-628.

4. Olszewski PK, Bomberg EM, Grace MK. Alpha-melanocyte stimulating hormone and ghrelin: central interaction in feeding control. Peptides. 2007;28:2084-2089.

5. Konig S, Luger TA, Scholzen TE. Monitoring neuropeptidespecific proteases: processing of the proopiomelanocortin peptides adrenocorticotropin and alpha-melanocyte-stimulating hormone in the skin. Exp Dermatol. 2006;15:751-761.

6. Qian Gao, Tamas L Horvath. Neurobiology of Feeding and Energy Expenditure. Annual Review of Neuroscience. 2007;(30)367-398 Ref Type: Generic.

7. Odya CE, Marinkovic DV, Hammon KJ, et al. Purification and properties of prolylcarboxypeptidase (angiotensinase C) from human kidney. J Biol Chem. 1978;253:5927-5931.

8. Dharmani M, Mustafa MR, Achike FI, et al. Effects of angiotensin 1-7 on the actions of angiotensin II in the renal and mesenteric vasculature of hypertensive and streptozotocin-induced diabetic rats. Eur J Pharmacol. 2007;561:144-150. 
9. Kassiri Z, Zhong J, Guo D, et al. Loss of angiotensin-converting enzyme 2 accelerates maladaptive left ventricular remodeling in response to myocardial infarction. Circ Heart Fail. 2009;2:446-455.

10. Giani JF, Gironacci MM, Munoz MC, et al. Angiotensin-(1-7) has a dual role on growth-promoting signalling pathways in rat heart in vivo by stimulating STAT3 and STAT5a/b phosphorylation and inhibiting angiotensin II-stimulated ERK1/2 and Rho kinase activity. Exp Physiol. 2008;93:570-578.

11. Nie W, Yan H, Li S, et al. Angiotensin-(1-7) enhances angiotensin II induced phosphorylation of ERK1/2 in mouse bone marrow-derived dendritic cells. Mol Immunol. 2009;46:355-361.

12. Rice GI, Thomas DA, Grant PJ, et al. Evaluation of angiotensinconverting enzyme (ACE), its homologue ACE2 and neprilysin in angiotensin peptide metabolism. Biochem J. 2004;383:45-51.

13. Huentelman MJ, Grobe JL, Vazquez J, et al. Protection from angiotensin II-induced cardiac hypertrophy and fibrosis by systemic lentiviral delivery of ACE2 in rats. Exp Physiol. 2005;90:783-790.

14. Felix D, Khosla MC, Barnes KL, et al. Neurophysiological responses to angiotensin-(1-7). Hypertension. 1991;17:1111-1114.

15. Gammelgaard I, Wamberg S, Bie P. Systemic effects of angiotensin III in conscious dogs during acute double blockade of the reninangiotensin-aldosterone-system. Acta Physiol (Oxf). 2006;188: 129-138.

16. Al-Aloul B, Li JM, Benditt D, et al. Atrial fibrillation associated with hypokalemia due to primary hyperaldosteronism (Conn's syndrome). Pacing Clin Electrophysiol. 2006;29:1303-1305.

17. Shariat-Madar Z, Mahdi F, Schmaier AH. Identification and characterization of prolylcarboxypeptidase as an endothelial cell prekallikrein activator. J Biol Chem. 2002;277:17962-17969.

18. Zhao Y, Qiu Q, Mahdi F, et al. Assembly and activation of HK-PK complex on endothelial cells results in bradykinin liberation and $\mathrm{NO}$ formation. Am J Physiol Heart Circ Physiol. 2001;280:H1821-H1829.

19. Colman RW, Schmaier AH. Contact system: a vascular biology modulator with anticoagulant, profibrinolytic, antiadhesive, and proinflammatory attributes. Blood. 1997;90:3819-3843.

20. Adams GN, Zhou Y, Larusch G, et al. Prolylcarboxypeptidase murine hypomorphs are hypertensive and prothrombotic. Journal of Thrombosis and Haemostasis 7 Supplement 2, XXII ISTH Congress, Abstract OC-MO-128. 2009. Ref Type: Abstract.

21. Piepoli MF, Scott AC, Capucci A, et al. Skeletal muscle training in chronic heart failure. Acta Physiol Scand. 2001;171:295-303.

22. Scott AC, Wensel R, Davos CH, et al. Skeletal muscle reflex in heart failure patients: role of hydrogen. Circulation. 2003;107:300-306.

23. Scott AC, Wensel R, Davos CH, et al. Putative contribution of prostaglandin and bradykinin to muscle reflex hyperactivity in patients on Ace-inhibitor therapy for chronic heart failure. Eur Heart $J$. 2004;25:1806-1813.

24. Mallela J, Yang J, Shariat-Madar Z. Prolylcarboxypeptidase: a cardioprotective enzyme. Int J Biochem Cell Biol. 2009;41:477-481.

25. Catania A, Rajora N, Capsoni F, et al. The neuropeptide alpha-MSH has specific receptors on neutrophils and reduces chemotaxis in vitro. Peptides. 1996;17:675-679.

26. Wallingford N, Perroud B, Gao Q, et al. Prolylcarboxypeptidase regulates food intake by inactivating alpha-MSH in rodents. $J$ Clin Invest. 2009;119:2291-2303.

27. Chiao H, Foster S, Thomas R, et al. Alpha-melanocyte-stimulating hormone reduces endotoxin-induced liver inflammation. J Clin Invest. 1996;97:2038-2044.

28. Kim F, Pham M, Maloney E, et al. Vascular inflammation, insulin resistance, and reduced nitric oxide production precede the onset of peripheral insulin resistance. Arterioscler Thromb Vasc Biol. 2008;28:1982-1988.

29. Pieper GM, Dondlinger L. Glucose elevations alter bradykinin-stimulated intracellular calcium accumulation in cultured endothelial cells. Cardiovasc Res. 1997;34:169-178.

30. Bullo M, Casas-Agustench P, migo-Correig P, et al. Inflammation, obesity and comorbidities: the role of diet. Public Health Nutr. 2007;10:1164-1172.
31. Kaneki M, Shimizu N, Yamada D, et al. Nitrosative stress and pathogenesis of insulin resistance. Antioxid Redox Signal. 2007;9: 319-329.

32. Tai MH, Weng WT, Lo WC, et al. Role of nitric oxide in alphamelanocyte-stimulating hormone-induced hypotension in the nucleus tractus solitarii of the spontaneously hypertensive rats. J Pharmacol Exp Ther. 2007;321:455-461.

33. DeBold CR, Menefee JK, Nicholson WE, et al. Proopiomelanocortin gene is expressed in many normal human tissues and in tumors not associated with ectopic adrenocorticotropin syndrome. Mol Endocrinol. 1988;2:862-870.

34. Tatro JB, Reichlin S. Specific receptors for alpha-melanocyte-stimulating hormone are widely distributed in tissues of rodents. Endocrinology. 1987;121:1900-1907.

35. Young JI, Otero V, Cerdan MG, et al. Authentic cell-specific and developmentally regulated expression of pro-opiomelanocortin genomic fragments in hypothalamic and hindbrain neurons of transgenic mice. J Neurosci. 1998; 18:6631-6640.

36. Voisey J, Carroll L, van DA. Melanocortins and their receptors and antagonists. Curr Drug Targets. 2003;4:586-597.

37. Cool DR, Normant E, Shen F, et al. Carboxypeptidase E is a regulated secretory pathway sorting receptor: genetic obliteration leads to endocrine disorders in Cpe(fat) mice. Cell. 1997;88:73-83.

38. Rouille Y, Duguay SJ, Lund K, et al. Proteolytic processing mechanisms in the biosynthesis of neuroendocrine peptides: the subtilisin-like proprotein convertases. Front Neuroendocrinol. 1995;16:322-361.

39. Guo L, Munzberg H, Stuart RC, et al. N-acetylation of hypothalamic alpha-melanocyte-stimulating hormone and regulation by leptin. Proc Natl Acad Sci U S A. 2004;101:11797-11802.

40. Chhajlani V, Wikberg JE. Molecular cloning and expression of the human melanocyte stimulating hormone receptor cDNA. FEBS Lett. 1992;309:417-420.

41. Cone RD, Mountjoy KG, Robbins LS, et al. Cloning and functional characterization of a family of receptors for the melanotropic peptides. Ann N Y Acad Sci. 1993;680:342-363.

42. Gantz I, Miwa H, Konda Y, et al. Molecular cloning, expression, and gene localization of a fourth melanocortin receptor. J Biol Chem. 1993;268:15174-15179.

43. Roselli-Rehfuss L, Mountjoy KG, Robbins LS, et al. Identification of a receptor for gamma melanotropin and other proopiomelanocortin peptides in the hypothalamus and limbic system. Proc Natl Acad Sci US A. 1993;90:8856-8860.

44. Konda Y, Gantz I, DelValle J, et al. Interaction of dual intracellular signaling pathways activated by the melanocortin-3 receptor. J Biol Chem. 1994;269:13162-13166.

45. Kojima I, Kojima K, Rasmussen H. Role of calcium and cAMP in the action of adrenocorticotropin on aldosterone secretion. J Biol Chem. $1985 ; 260: 4248-4256$

46. Englaro W, Rezzonico R, Durand-Clement M, et al. Mitogen-activated protein kinase pathway and AP-1 are activated during cAMP-induced melanogenesis in B-16 melanoma cells. J Biol Chem. 1995;270: 24315-24320.

47. Buggy JJ. Binding of alpha-melanocyte-stimulating hormone to its G-protein-coupled receptor on B-lymphocytes activates the Jak/STAT pathway. Biochem J. 1998;331(Pt 1):211-216.

48. Rodrigues AR, Pignatelli D, Almeida H, et al. Melanocortin 5 receptor activates ERK1/2 through a PI3K-regulated signaling mechanism. Mol Cell Endocrinol. 2009;303:74-81.

49. Wikberg JE. Melanocortin receptors: perspectives for novel drugs. Eur J Pharmacol. 1999;375:295-310.

50. Donatien PD, Hunt G, Pieron C, et al. The expression of functional MSH receptors on cultured human melanocytes. Arch Dermatol Res. 1992;284:424-426.

51. Suzuki I, Cone RD, Im S, et al. Binding of melanotropic hormones to the melanocortin receptor MC1R on human melanocytes stimulates proliferation and melanogenesis. Endocrinology. 1996;137: $1627-1633$. 
52. Xia Y, Skoog V, Muceniece R, et al. Polyclonal antibodies against human melanocortin $\mathrm{MC} 1$ receptor: preliminary immunohistochemical localisation of melanocortin MC1 receptor to malignant melanoma cells. Eur J Pharmacol. 1995;288:277-283.

53. Mountjoy KG, Robbins LS, Mortrud MT, et al. The cloning of a family of genes that encode the melanocortin receptors. Science. 1992;257:1248-1251.

54. Chhajlani V. Distribution of cDNA for melanocortin receptor subtypes in human tissues. Biochem Mol Biol Int. 1996;38:73-80.

55. Xia Y, Wikberg JE, Chhajlani V. Expression of melanocortin 1 receptor in periaqueductal gray matter. Neuroreport. 1995;6:2193-2196.

56. Hartmeyer M, Scholzen T, Becher E, et al. Human dermal microvascular endothelial cells express the melanocortin receptor type 1 and produce increased levels of IL-8 upon stimulation with alpha-melanocytestimulating hormone. J Immunol. 1997;159:1930-1937.

57. Wong KY, Rajora N, Boccoli G, et al. A potential mechanism of local anti-inflammatory action of alpha-melanocyte-stimulating hormone within the brain: modulation of tumor necrosis factor-alpha production by human astrocytic cells. Neuroimmunomodulation. 1997;4: 37-41.

58. Star RA, Rajora N, Huang J, et al. Evidence of autocrine modulation of macrophage nitric oxide synthase by alpha-melanocyte-stimulating hormone. Proc Natl Acad Sci U S A. 1995;92:8016-8020.

59. Boston BA, Cone RD. Characterization of melanocortin receptor subtype expression in murine adipose tissues and in the 3T3-L1 cell line. Endocrinology. 1996;137:2043-2050.

60. Luger TA, Scholzen T, Grabbe S. The role of alpha-melanocytestimulating hormone in cutaneous biology. J Investig Dermatol Symp Proc. 1997;2:87-93.

61. Lipton JM, Catania A. Anti-inflammatory actions of the neuroimmunomodulator alpha-MSH. Immunol Today. 1997;18:140-145.

62. Manna SK, Aggarwal BB. Alpha-melanocyte-stimulating hormone inhibits the nuclear transcription factor NF-kappa B activation induced by various inflammatory agents. J Immunol. 1998;161: 2873-2880.

63. Schioth HB, Chhajlani V, Muceniece R, et al. Major pharmacological distinction of the ACTH receptor from other melanocortin receptors. Life Sci. 1996;59:797-801.

64. Xia Y, Wikberg JE. Localization of ACTH receptor mRNA by in situ hybridization in mouse adrenal gland. Cell Tissue Res. 1996;286:63-68.

65. Slominski A, Ermak G, Mihm M. ACTH receptor, CYP11A1, CYP17 and CYP21A2 genes are expressed in skin. J Clin Endocrinol Metab. 1996;81:2746-2749.

66. Kapas S, Hagi-Pavli E, Brown DW, et al. Direct effects of corticotrophin on oral keratinocyte cell proliferation. Eur J Biochem. 1998;256: 75-79.

67. Gantz I, Tashiro T, Barcroft C, et al. Localization of the genes encoding the melanocortin-2 (adrenocorticotropic hormone) and melanocortin-3 receptors to chromosomes $18 \mathrm{p} 11.2$ and $20 \mathrm{q} 13.2-\mathrm{q} 13.3$ by fluorescence in situ hybridization. Genomics. 1993;18:166-167.

68. Mountjoy KG, Wong J. Obesity, diabetes and functions for proopiomelanocortin-derived peptides. Mol Cell Endocrinol. 1997;128:171-177.

69. Gantz I, Konda Y, Tashiro T, et al. Molecular cloning of a novel melanocortin receptor. J Biol Chem. 1993;268:8246-8250.

70. Ollmann MM, Wilson BD, Yang YK, et al. Antagonism of central melanocortin receptors in vitro and in vivo by agouti-related protein. Science. 1997;278:135-138.

71. Bagnol D, Lu XY, Kaelin CB, et al. Anatomy of an endogenous antagonist: relationship between Agouti-related protein and proopiomelanocortin in brain. J Neurosci. 1999;19:RC26.

72. Jegou S, Boutelet I, Vaudry H. Melanocortin-3 receptor mRNA expression in pro-opiomelanocortin neurones of the rat arcuate nucleus. J Neuroendocrinol. 2000;12:501-505.

73. Cowley MA, Smart JL, Rubinstein M, et al. Leptin activates anorexigenic POMC neurons through a neural network in the arcuate nucleus. Nature. 2001;411:480-484.
74. Marks DL, Hruby V, Brookhart G, et al. The regulation of food intake by selective stimulation of the type 3 melanocortin receptor (MC3R). Peptides. 2006;27:259-264.

75. Li WD, Joo EJ, Furlong EB, et al. Melanocortin 3 receptor (MC3R) gene variants in extremely obese women. Int J Obes Relat Metab Disord. 2000;24:206-210.

76. Schalin-Jantti C, Valli-Jaakola K, Oksanen L, et al. Melanocortin-3receptor gene variants in morbid obesity. Int J Obes Relat Metab Disord. 2003;27:70-74.

77. Lee YS, Poh LK, Loke KY. A novel melanocortin 3 receptor gene (MC3R) mutation associated with severe obesity. J Clin Endocrinol Metab. 2002;87:1423-1426.

78. Rached M, Buronfosse A, Begeot M, et al. Inactivation and intracellular retention of the human $\mathrm{I} 183 \mathrm{~N}$ mutated melanocortin 3 receptor associated with obesity. Biochim Biophys Acta. 2004;1689:229-234.

79. Tao YX. Functional characterization of novel melanocortin-3 receptor mutations identified from obese subjects. Biochim Biophys Acta. 2007;1772:1167-1174.

80. Calton MA, Ersoy BA, Zhang S, et al. Association of functionally significant Melanocortin-4 but not Melanocortin-3 receptor mutations with severe adult obesity in a large North American case-control study. Hum Mol Genet. 2009;18:1140-1147.

81. Mountjoy KG, Mortrud MT, Low MJ, et al. Localization of the melanocortin-4 receptor (MC4-R) in neuroendocrine and autonomic control circuits in the brain. Mol Endocrinol. 1994;8:1298-1308.

82. Huszar D, Lynch CA, Fairchild-Huntress V, et al. Targeted disruption of the melanocortin-4 receptor results in obesity in mice. Cell. 1997;88:131-141.

83. Yen TT, Gill AM, Frigeri LG, et al. Obesity, diabetes, and neoplasia in yellow A(vy)/-mice: ectopic expression of the agouti gene. FASEB J. 1994;8:479-488.

84. Marks DL, Ling N, Cone RD. Role of the central melanocortin system in cachexia. Cancer Res. 2001;61:1432-1438.

85. Fathi Z, Iben LG, Parker EM. Cloning, expression, and tissue distribution of a fifth melanocortin receptor subtype. Neurochem Res. 1995;20:107-113.

86. bdel-Malek ZA. Melanocortin receptors: their functions and regulation by physiological agonists and antagonists. Cell Mol Life Sci. 2001;58:434-441.

87. Chen W, Kelly MA, Opitz-Araya X, et al. Exocrine gland dysfunction in MC5-R-deficient mice: evidence for coordinated regulation of exocrine gland function by melanocortin peptides. Cell. 1997;91: 789-798.

88. Hatta N, Dixon C, Ray AJ, et al. Expression, candidate gene, and population studies of the melanocortin 5 receptor. J Invest Dermatol. 2001;116:564-570.

89. Chhajlani V, Muceniece R, Wikberg JE. Molecular cloning of a novel human melanocortin receptor. Biochem Biophys Res Commun. 1996;218:638

90. Chagnon YC, Chen WJ, Perusse L, et al. Linkage and association studies between the melanocortin receptors 4 and 5 genes and obesity-related phenotypes in the Quebec Family Study. Mol Med. 1997;3:663-673.

91. Watson SJ, Akil H, Richard CW III, et al. Evidence for two separate opiate peptide neuronal systems. Nature. 1978;275:226-228.

92. Jacobowitz DM, O’Donohue TL. alpha-Melanocyte stimulating hormone: immunohistochemical identification and mapping in neurons of rat brain. Proc Natl Acad Sci U S A. 1978;75:6300-6304.

93. Cone RD. Anatomy and regulation of the central melanocortin system. Nat Neurosci. 2005;8:571-578.

94. Broberger C, Johansen J, Johansson C, et al. The neuropeptide Y/agouti gene-related protein (AGRP) brain circuitry in normal, anorectic, and monosodium glutamate-treated mice. Proc Natl Acad Sci U S A. 1998;95:15043-15048.

95. Shintani M, Ogawa Y, Ebihara K, et al. Ghrelin, an endogenous growth hormone secretagogue, is a novel orexigenic peptide that antagonizes leptin action through the activation of hypothalamic neuropeptide Y/Y1 receptor pathway. Diabetes. 2001;50:227-232. 
96. Niswender KD, Baskin DG, Schwartz MW. Insulin and its evolving partnership with leptin in the hypothalamic control of energy homeostasis. Trends Endocrinol Metab. 2004;15:362-369.

97. Challis BG, Coll AP, Yeo GS, et al. Mice lacking pro-opiomelanocortin are sensitive to high-fat feeding but respond normally to the acute anorectic effects of peptide-YY(3-36). Proc Natl Acad Sci U S A. 2004;101:4695-4700.

98. Kamegai J, Tamura H, Shimizu T, et al. Central effect of ghrelin, an endogenous growth hormone secretagogue, on hypothalamic peptide gene expression. Endocrinology. 2000;141:4797-4800.

99. Rao TL, Kokare DM, Sarkar S, et al. GABAergic agents prevent alpha-melanocyte stimulating hormone induced anxiety and anorexia in rats. Pharmacol Biochem Behav. 2003;76:417-423.

100. Cummings DE, Purnell JQ, Frayo RS, et al. A preprandial rise in plasma ghrelin levels suggests a role in meal initiation in humans. Diabetes. 2001;50:1714-1719.

101. Tschop M, Wawarta R, Riepl RL, et al. Post-prandial decrease of circulating human ghrelin levels. J Endocrinol Invest. 2001;24: RC19-RC21.

102. Ariyasu H, Takaya K, Tagami T, et al. Stomach is a major source of circulating ghrelin, and feeding state determines plasma ghrelin-like immunoreactivity levels in humans. J Clin Endocrinol Metab. 2001;86:4753-4758.

103. Tschop M, Weyer C, Tataranni PA, et al. Circulating ghrelin levels are decreased in human obesity. Diabetes. 2001;50:707-709.

104. Hewson AK, Dickson SL. Systemic administration of ghrelin induces Fos and Egr-1 proteins in the hypothalamic arcuate nucleus of fasted and fed rats. J Neuroendocrinol. 2000;12:1047-1049.

105. Cowley MA, Smith RG, Diano S, et al. The distribution and mechanism of action of ghrelin in the CNS demonstrates a novel hypothalamic circuit regulating energy homeostasis. Neuron. 2003;37:649-661.

106. Shaw AM, Irani BG, Moore MC, et al. Ghrelin-induced food intake and growth hormone secretion are altered in melanocortin 3 and 4 receptor knockout mice. Peptides. 2005;26:1720-1727.

107. Wilding JP, Ajala MO, Lambert PD, et al. Additive effects of lactation and food restriction to increase hypothalamic neuropeptide Y mRNA in rats. J Endocrinol. 1997;152:365-369.

108. Clark JT, Kalra PS, Crowley WR, et al. Neuropeptide Y and human pancreatic polypeptide stimulate feeding behavior in rats. Endocrinology. 1984;115:427-429.
109. Levine AS, Morley JE. Neuropeptide Y: a potent inducer of consummatory behavior in rats. Peptides. 1984;5:1025-1029.

110. Zarjevski N, Cusin I, Vettor R, et al. Chronic intracerebroventricular neuropeptide- $\mathrm{Y}$ administration to normal rats mimics hormonal and metabolic changes of obesity. Endocrinology. 1993;133:1753-1758.

111. Tiesjema B, Adan RA, Luijendijk MC, et al. Differential effects of recombinant adeno-associated virus-mediated neuropeptide $\mathrm{Y}$ overexpression in the hypothalamic paraventricular nucleus and lateral hypothalamus on feeding behavior. J Neurosci. 2007;27: 14139-14146.

112. Yang L, Scott KA, Hyun J, et al. Role of dorsomedial hypothalamic neuropeptide $\mathrm{Y}$ in modulating food intake and energy balance. J Neurosci. 2009;29:179-190.

113. Garcia de YE, Li S, Fournier A, et al. Regulation of proopiomelanocortin gene expression by neuropeptide $\mathrm{Y}$ in the rat arcuate nucleus. Brain Res. 1995;674:112-116.

114. Abid K, Rochat B, Lassahn PG, et al. Kinetic study of neuropeptide Y (NPY) proteolysis in blood and identification of NPY3-35: a new peptide generated by plasma kallikrein. J Biol Chem. 2009;284: 24715-24724.

115. Watson B Jr, Nowak NJ, Myracle AD, et al. The human angiotensinase $\mathrm{C}$ gene (HUMPCP) maps to $11 \mathrm{q} 14$ within $700 \mathrm{~kb}$ of D11S901: a candidate gene for essential hypertension. Genomics. 1997;44: 365-367.

116. Wang L, Feng Y, Zhang Y, et al. Prolylcarboxypeptidase gene, chronic hypertension, and risk of preeclampsia. Am J Obstet Gynecol. 2006;195:162-171.

117. ZHANG Yan, Hong Xiu-mei, Hou-xun, et al. E112D polymorphism in the prolylcarboxypeptidase gene is associated with blood pressure response to benazepril in Chinese hypertensive patients. Chinese Med J. 2009;122:2461-2465.

118. Arai K, Shibasaki T. [Genetic abnormalities of regulatory mechanism of appetite]. Nippon Rinsho. 2001;59:449-455.

119. Ichiyama T, Sakai T, Catania A, et al. Systemically administered alpha-melanocyte-stimulating peptides inhibit NF-kappaB activation in experimental brain inflammation. Brain Res. 1999;836:31-37.

\section{Publish your work in this journal}

Diabetes, Metabolic Syndrome and Obesity: Targets and Therapy is an international, peer-reviewed open-access journal committed to the rapid publication of the latest laboratory and clinical findings in the fields of diabetes, metabolic syndrome and obesity research. Original research, review, case reports, hypothesis formation, expert opinion and commentaries are all considered for publication. The manuscript management system is completely online and includes a very quick and fair peer-review system, which is all easy to use. Visit http://www.dovepress.com/testimonials.php to read real quotes from published authors. 